\title{
Editorial: Big Science: Individual hopes, collective risks
}

\section{WENDY HARCOURT}

As you read this issue of Development be prepared to plunge into series of complex and as yet unresolved debates around some of the most vital issues of our time. Development 49.4 looks at the ramifications of new and emerging technologies on people's well being and rights with a set of thought-provoking articles that open up the dialogue on reproductive assisted technologies, nanotechnology, genetics and disability and what they imply for human rights, bodily integrity, nutrition, safety, social justice and development.

Some of the questions on the table are: What do new and emerging technologies imply for the well being of the poor and marginalized groups living in both the global South and North? What are the gender issues particularly around the control and management of reproduction? What is the impact of nanotechnology as it moves from the laboratory to industrial production? Who is deciding to promote which technologies? Where is the research being produced, where is it being applied, with whose money and whose knowledge? Where and how can poorer countries receive the expertise to understand what is in their interest and what are the right decisions to make? What are the implications for governance at the local and global level? Which institutions can manage this? What are the different issues for people living in the North and South? What are the larger policy and ethical implications for development as a whole?

In short, the articles take a candid look at major ethical, social, economic and political consequences of the latest developments in science and technology and the diverse ramifications for all of humanity. And, paradoxically, they point out the difficulty of promoting an informed and open public dialogue that is free from technical language and legalities so that the ordinary person can follow it.

It has been a fascinating issue to put together. It has forced me to rethink a vast range of issues from nutrition, biopiracy, public health, nanotechnology, medicine, gender equality and disability and impairment. I have had to confront worrying issues about how nature, poor people, particularly women's bodies and 'disabled' bodies continue to be the battleground for many bioethical and genetic issues that are determining our lives and futures. After editing this issue, I am convinced that new and emerging technologies not only touch the very fabric of our lives, transforming social and economic 
development but do so in ways our current understanding of science, ethics and social responsibilities obscure. In order to accommodate what Mooney and others call the tsunami of nanotechnology, for example, we need urgently to find new conceptual approaches to science, medicine, health, well being and even humanity.

It was ambitious for Development to bring together new debates on nanotechnologies, disabilities, health and well being and assisted reproductive technologies from a development, gender and social justice perspective. I have been privileged to work with Gregor Wolbring and Marsha Tyson Darling who have taken time from their important academic and advocacy work to help me bring together committed opinion makers of economic, ethical and political debates on new and emerging biotechnologies and development. The authors are medical, physical science and social science, disability studies and ability studies researchers, civil rights activists, medical practitioners, public health advocates, disability and women's rights advocates, environmentalists and indigenous rights activists. They offer challenging perspectives emerging from their work in key research and civil society institutes in North America, South Asia and Latin America.

The journal issue takes up four major sets of debates:

- Ethical, political, economic and social concerns arising from genomics research/new genetics and nanotechnologies;

- the impact of these technologies on development policy, health, food and the environment;

- the concerns new technologies raise in today's debates around disability, rights and health; and

- the gender dimension of new biotechnologies especially around assisted reproduction.

While I urge readers to delve into the articles to glean all they can from the contributions, I would like to highlight briefly what struck me as the most important arguments raised by the authors.

Many of the articles open up questions from quite different parameters about science and technology, asking us to understand and indeed publicly question the legal, ethical, social, racist, where science is conducted and planned. They all point out the dearth of spaces to debate openly these fundamental concerns around new and emerging technologies.

Daniel Sarewitz puts it starkly: public science is failing to be responsible. For him,

'[I]f we are to have any prospect of guiding and modulating the advance of rapidly emerging transformational technologies in accord with goals, values, and interests other than those dictated by the marketplace and the military, then the responsibility of the scientist must expand from doing the right thing as an individual, to participating in the reflexive process of creating institutional consciousness.' (Sarewitz, 2006) ${ }^{1}$

Pat Mooney, Director of ETC Group, a leading civil society research and advocacy group (see this edition of Window on the World) in his lead article contrasts what science and capitalism have achieved for the world (see the table 'Giving Credit Where Credit Is Due') with the nastier 'side dishes' in relation to social and economic impacts. He illustrates the double-edged sword of science, technology and capitalism with obesity, arguing that the technology system must accept responsibility for the explosion in what the World Health Organization calls 'globesity'.

His forceful critique of science, technology and capitalism is echoed in the articles which argue that scientific responsibility and technological innovation have moved onto a new level taking into account the social economic and ethical context. Sujatha Byravan explores how the use of DNA typing in forensics and immigration, given the current climate of fear since September 11, 2001 could legitimize discrimination and give rise to a new apartheid. She warns that there are many troubling aspects in using DNA. For her the use of biological science in this context smacks of eugenics and social control based on what is ultimately an unacknowledged racism. Rosario Isasi and George Annas trace the development of the United Nations Declaration on Human Cloning, demonstrating the difficulty of reaching an international consensus, and how the current declaration fails to address the ethical issues surrounding cloning. 
Anuradha Mittal raises questions about how nanotechnology - the manipulation of matter on the scale of atoms and molecules - is planning to provide the next revolution in food and agriculture industry. She argues that this powerful new technology is being rushed onto the market by corporations before even basic safety concerns are addressed. She points to the many downsides in relation to health and environmental threats that are being ignored as the world's largest food and beverage corporations push nanotechnology-based solutions:

'Given the environmental and health risks and concerns around the impact of such technologies on small farmers and developing countries, there is a need for a wide debate and true public participation from all sectors, including farmers, civil society organizations, and social movements.' (Mittal, 2006)

While Mittal brings out the disturbing dimension of technology in relation to food safety, Beth Burrows writes a very candid article about human genome project, or as some indigenous people have named it the 'vampire project'. She recollects an indigenous woman, Jeanette Armstrong's words to her: 'You destroyed our history and now, now it seems you come to suck the marrow from our bones'. Burrows asks that there be far more debate and record of such major scientific projects so that people can judge how well independent advice' to the nation on science and its impact on society has been given.

The conspiracy of biopiracy by science, industry and others is flagged in several articles. Sarah Franklin in her review of books on bio-economics and Chris Hamilton in his article both point to the pressure on intellectual property rights (IPR) regimes to adjust rapidly to new developments in biotechnology and in the global economy. According to Hamilton, 'biopiracy is situated at the crossroads of IPR, biotechnology and development' involving a complex set of debates around the ethics of 'biocapital' that go beyond narrow economic terms.

Nanotechnology emerges as a key economic phenomenon that the authors warn will have dire effects on commodity markets, will disrupt trade and eliminate jobs. The impact of nanotechnology on development is complex and not well understood socially and economically. Debra Bennett Woods discusses the excitement and dangers around nanotechnology. She acknowledges that nanotechnology holds great potential as an enabler of a wide range of biotechnologies that will change the face of medicine and may eventually alter the very definition of human health. But, she points out that the major differences in health risks between the South and North could very well increase if new technology research and development remains targeted at the diseases of the North and individual enhancement, with dire consequences for issues of access, consent and human identity.

Michele Mekel asks that we take into account the ethical, legal and social implications of nanotechnology not only in relation to health, and safety issues but indeed, in relation to the constitution of human nature. This is something disability rights people are also extremely concerned about (see below). She suggests we break down the hyperbole around the marketing of nanotechnologies and go beyond the 'nanobabble' in both science and technology and discuss much more candidly the ethical and social issues in the context of funding interests. Guillermo Foladori and Noela Invernizzi take a look at the underside of nanomedicine in relation to health and poverty. While nanotechnology may hold out great technological hope, this hope has to be mediated by awareness of major social and economic barriers, particularly in the South. Jim Thomas from the ETC Group puts it bluntly when he argues that nanotechnology is a technological tsunami. $\mathrm{He}$ warns,

that the full force of the nanotech wave is set to hit within the next 3-7 years, disrupting North and South, rich and poor alike. The first products and applications of nanotechnology are already on the market and the time is well overdue to begin preparing defences for turmoil ahead.' (Thomas, 2006)

Among the most provoking articles are those that look at the impact of new and emerging technologies, including nanotechnology, on disability and rights. Gregor Wolbring opens up the conversation in his lead article on the promises and perils 
of nanotechnology and nano-bio-info-cogno-synbio (NBICS) for the global community when understanding of disability (he speaks of 'disabilism'). As we put together this issue of Development, many hopes have been raised around the agreement on the text of the UN Convention on the Rights of Persons with Disabilities which was reached on 27 August 2006. The convention will be formally sent to the General Assembly for adoption in September 2006. It will then be open for signing and ratification by all countries. http:// www.un.org/disabilities/convention/index.shtml.

The Convention is seen as trend setting in relation to the rights of the disabled. Pia Rockhold in her review of disability over time argues that disability does not exist where equity, equality and social justice rules. She is optimistic that the UN Convention protecting the rights of people with disabilities will hopefully mark the beginning of a new era, where the global goal will be a steady increase in the 'Gross National Happiness' around the world. But Wolbring in his comments in Last Word points out that: 'People concerned about the rights of disabled people have to follow very closely debates around personhood and what is being defined as a person in order to follow how the applicability of the Convention might change.'

Gender and disability is one strong area in the Convention and the gender dimension cuts through this journal issue, particularly the sensitive debate around disability and reproductive technologies. Asha Hans points out that the 200 million disabled women in the South are poor and enclosed within gender-blind patriarchal systems, where on the one hand women's wombs are open to the free market place for use, while on the other women are denied basic rights and justice. Disabled women need to have the knowledge and space to question and contest the use of these technologies in the context of use of human bodies. She argues there is an unethical divide in the law, which considers testing for sex selection as illegal while testing for disabilities such as Down Syndrome as legal. Women who decide to have children but do not meet the standards of perfection and have such children rarely have so- pity. The marketing of the next generation assisted fertility technologies is another example of this divide, and while it is used for attaining the perfect it is also used to force family planning strategies. In this unrecognized or silently accepted eugenics, women are often forced to use new reproductive technologies. Even as women are in the process of organizing themselves across the world to seek justice, women with disabilities are limited in this movement. Along with Ashok Hans and Reena Moranty in their discussion on disasters and disability rights, Hans asks for a greater voice of disabled people.

Rachel Hurst shows how deeply our prejudice (or disablism, according to Wolbring) is in relation to the search for the perfect. She asks whose idea of perfection is the right one:

\begin{abstract}
'In today's rights-based world, nobody would publicly say that to be different in relation to gender or ethnicity was a bad thing. But it is an accepted belief that to be disabled is bad and disabled people should be relieved of their suffering, and this 'doing good' gives humanitarian gold stars to those who seek otherwise. The positive attributes of disability seem to be too much for many people to believe or understand.' (Hurst, 2006)
\end{abstract}

In the articles on Assisted Reproductive Technologies (ARTS), gender injustice and the ethical and political dimensions are taken up in case studies from around the world. This set of articles build on the dialogue already begun in Development 49.1 on women's rights and development and Development 48.4 on sexual and reproductive rights and health globally. Wendy Chavkin argues that ARTS are an important public health and social phenomena. As she says,

Although ARTS imply profound challenges to notions of biological kinship and parenthood, to marital relationships, to definitions of identity varied societies and religions have incorporated them so as to minimize these challenges and perpetuate the group status quo. In short, ARTS does not guarantee a shake up in gender roles or wider possibilities for women. In fact, in some of these settings ART use is melded into longstanding pro-natalism, in a way that constricts rather than widens options for women to control their fertility and their roles in the society' (Chavkin, 2006) 
Manjeer Muherjee and Sarojini N.B. writing on behalf of Sama - Resource Group for Women and Health - show how the intersection of patriarchal traditions, the scientific medical establishment and the global market in India have indeed produced a standardization of new reproductive technologies that threatens rather than sustains women's rights. In their survey of the astonishingly rapid expansion of private clinics offering ARTS in India, Shree Mulay and Emily Gibson examine their negative effect on the public health sector as well as the feeble attempts by the Indian state to regulate this industry and its implications for women's reproductive rights and health. Their findings are paralleled in Liliana Acero's study of the way new reproductive technologies are impacting upon women's bodies, tissues, reproductive capacities and rights in Latin America given clandestine abortions and lack of regulation of ARTS. She joins Marcy Darnovsky's in calling for a platform for gender and social genetics justice in opposition to 'designer babies' and 'designer public health' with a universal and democratic access to medical technologies and protocols, a distribution of resources towards global equity in health and democratic control and precaution regarding ARTS.

Undoubtedly, we have to heed the call that we are facing a 'brave new world' every bit as frightening as Huxley predicted, one that requires far more public knowledge and open debate based on reliable knowledge. Certainly, the thoughtful insights provided by the contributions to this journal issue will help. Many of them belong to networks and institutions that can be contacted easily through email or on the Web (see Who's Who and Window on the World). I encourage all readers to take the warnings seriously and not sit back but join in the fight for greater ethical responsibility in the development and application of new and emerging technologies. As Gregor Wolbring's bi-weekly column states, 'The Choice is Yours'.

\section{Note}

1 This quotation and all citations that follow are taken from articles published in this issue of Development, vol. 49 , No. 4. 